$$
3
$$

9 Key Points: and warming between the poles stronger lapse-rate feedback and Antarctic amplification

\title{
Antarctic elevation drives hemispheric asymmetry in polar lapse-rate climatology and feedback
}

\author{
Corresponding author: Lily Hahn (Ichahn@uw.edu) \\ Authors: L. C. Hahn', K. C. Armour ${ }^{1,2}$, D. S. Battisti', A. Donohoe ${ }^{3}$, A. G. Pauling', \\ and C. M. Bitz' \\ 'Department of Atmospheric Sciences, University of Washington, Seattle, WA, USA. \\ ${ }^{2}$ School of Oceanography, University of Washington, Seattle, WA, USA. \\ ${ }^{3}$ Polar Science Center, Applied Physics Lab, University of Washington, Seattle, WA, USA.
}

- Antarctic elevation causes asymmetry in climatological inversions, lapse-rate feedbacks,

- In model experiments with flattened Antarctica, strengthened inversions lead to

- Shortwave cloud feedback promotes seasonality in flat Antarctic warming; lapse-rate feedback more strongly promotes seasonality in Arctic 


\section{Abstract}

The lapse-rate feedback is the dominant driver of stronger warming in the Arctic than the Antarctic in simulations with increased $\mathrm{CO}_{2}$. While Antarctic surface elevation has been implicated in promoting a weaker Antarctic lapse-rate feedback, the mechanisms in which elevation impacts the lapse-rate feedback are still unclear. Here we suggest that weaker Antarctic warming under $\mathrm{CO}_{2}$ forcing stems from shallower, less intense climatological inversions due to limited atmospheric heat transport above the ice sheet elevation and elevation-induced katabatic winds. In slab ocean model experiments with flattened Antarctic topography, stronger climatological inversions support a stronger lapse-rate feedback and annual-mean Antarctic warming comparable to the Arctic under $\mathrm{CO}_{2}$ doubling. Unlike the Arctic, seasonality in warming over flat Antarctica is mainly driven by a negative shortwave cloud feedback which exclusively dampens summer warming, with a smaller contribution from the winter-enhanced lapse-rate feedback.

\section{Plain Language Summary}

Models project stronger surface warming in the Arctic than the Antarctic under climate change. A climate feedback in which more warming occurs near the surface than at higher altitudes in the atmosphere promotes this increased warming in the Arctic. Antarctica's surface elevation is thought to weaken this feedback in comparison to the Arctic, but how this occurs is unclear. Here we show that Antarctic elevation weakens surface warming by changing the base-state vertical temperature structure. When Antarctic topography is flattened in model experiments, Antarctica experiences more warming under climate change, resembling Arctic warming. Similarly to the Arctic, flat Antarctica warms most during the winter, but this seasonality is driven by different climate feedbacks in the Arctic versus Antarctic. These results indicate the importance of base-state temperatures for warming under climate change, and suggest that strong polar amplification is possible without local sea-ice loss.

\section{Introduction}

The Arctic has warmed about twice the global average in recent decades in a pattern

known as Arctic amplification (Serreze et al., 2009; Screen and Simmonds, 2010a). In contrast,

Antarctic amplification is not observed in the same timeframe, and Antarctic warming is

dwarfed by Arctic warming in $21^{\text {st }}$ century projections (Marshall et al., 2015; Smith et al., 2019).

While Antarctic warming is delayed in part by Southern Ocean upwelling and associated heat uptake (Collins et al., 20I3; Armour et al., 2016), global climate models also project weaker equilibrium warming for the Antarctic than the Arctic (e.g., Danabasoglu and Gent, 2009). In an evaluation of models in the fifth phase of the Coupled Model Intercomparison Project (CMIP5), 
Goosse et al. (2018) find that the lapse-rate feedback is the single greatest factor contributing to this hemispheric asymmetry in polar warming.

In a warming climate, a positive polar lapse-rate feedback results from stable temperature inversions which contribute to stronger warming near the surface than aloft, leading to inefficient longwave emission to space. In the Arctic, the ice-albedo feedback promotes surface warming and thus contributes to a more-positive lapse-rate feedback (Feldl et al., 2017; Graversen et al., 2014). Dai et al. (2019) have more recently argued that Arctic seaice loss enables the lapse-rate feedback via increased turbulent heat fluxes and upward longwave radiation, enhancing lower-tropospheric warming over newly opened ocean. These results align with evidence that sea-ice loss promotes seasonality in Arctic warming by enhancing winter heat transfer from the ocean to the atmosphere and strengthening winter longwave radiative feedbacks (e.g., Screen and Simmonds, 2010b; Bintanja and van der Linden, 2013). Given the proposed dependence of Arctic lower-tropospheric warming and lapse-rate feedback on sea-ice loss, a weaker Antarctic lapse-rate feedback may be driven by the persistence of the Antarctic ice sheet.

Using fully-coupled Community Earth System Model (CESM) experiments, Salzmann (2017) instead finds that Antarctic elevation drives the weaker Antarctic lapse-rate feedback. As the sign and magnitude of the lapse-rate feedback depends on base-state static stability (Cronin and Jansen, 2015; Payne et al., 2015), we expect Antarctic elevation to control the lapse-rate feedback through impacts on base-state inversions. Confinement of the radiatively-active atmospheric column over Antarctica to a shallower layer than in the Arctic may additionally weaken the lapse-rate feedback. 
With the mechanisms linking Antarctic elevation to a weaker lapse-rate feedback still unclear, we investigate hemispheric asymmetry in the polar lapse-rate feedback using slab ocean CESM experiments with present-day and flattened Antarctic topography under preindustrial and doubled $\mathrm{CO}_{2}$. We analyze Antarctic elevation impacts on climatological inversions, the lapse-rate feedback, and polar amplification, in addition to investigating the seasonality of warming in the flat Antarctic compared to the Arctic. These experiments provide insight into hemispheric polar warming differences, with an ultimate goal of better understanding the mechanisms behind polar amplification.

\section{Data and Methods}

\section{I Model Experiments}

To investigate hemispheric asymmetry in the lapse-rate feedback, we use CESM (Hurrell et al., 2013) version I.2.2 with the Community Atmosphere Model version 4 (CAM4; Neale et al., 2013). CAM4 has a horizontal resolution of $0.9^{\circ} \times 1.25^{\circ}$ and 26 vertical levels, with vertical grid spacing further described in Richter et al. (20I4). For all experiments, CAM4 is coupled to a slab ocean forced with a spatially heterogeneous monthly climatology of ocean heat flux convergence derived from a fully-coupled preindustrial control simulation (Bitz et al., 20I2). Differing from Salzmann (2017) in the use of a slab ocean rather than fully-coupled model, these experiments isolate the role of Antarctic elevation in determining the equilibrium climate response to $\mathrm{CO}_{2}$ forcing and exclude potential effects of ocean heat uptake changes on the lapse-rate feedback (e.g., Po-Chedley et al., 2018; Singh et al., 2018). CESM also uses the Community Land Model version 4 (CLM4; Oleson et al., 2010) and the Los Alamos Sea Ice Model version 4 (CICE4; Hunke and Lipscomb, 2008). 

control Antarctic, or with the elevation of Antarctica flattened to $0 \mathrm{~m}$ above sea level, referred to as the flat Antarctic. Branching from preindustrial runs for the control and flat Antarctic, $\mathrm{CO}_{2}$ is abruptly doubled from 285 to 570 ppm. We run each simulation for 50 years, and calculate climatologies over the final 30 years. Net top-of-atmosphere (TOA) energy imbalances of $-0.09 \mathrm{~W} / \mathrm{m}^{2}$ (control, preindustrial), $-0.06 \mathrm{~W} / \mathrm{m}^{2}$ (control, doubled $\mathrm{CO}_{2}$ ), $-0.14 \mathrm{~W} / \mathrm{m}^{2}$ (flat, preindustrial), and $-0.09 \mathrm{~W} / \mathrm{m}^{2}$ (flat, doubled $\mathrm{CO}_{2}$ ) indicate near equilibrium for all experiments in this period.

\subsection{Radiative Feedbacks}

We calculate the lapse-rate, Planck, surface-albedo, water-vapor, and cloud radiative feedbacks using the radiative kernel method (Shell et al., 2008; Soden et al., 2008). This method calculates radiative feedbacks as the product of (a) the change in radiative flux per unit change in a given climate variable, termed the radiative kernel, and (b) the modeled change in this climate variable normalized by the surface temperature change. While the Planck feedback is defined by propagating the surface temperature change through the entire troposphere, the lapse-rate feedback calculates the effect of departures from this vertically uniform temperature change. To calculate cloud feedbacks, the kernel method is used to determine the effect of noncloud variables (temperature, water vapor, and surface albedo) on the change in cloud radiative forcing $(\triangle \mathrm{CRF})$, and this cloud masking effect is subtracted from the total $\Delta C R F$ (Shell et al., 2008; Soden et al., 2008). We calculate the residual term by subtracting the kernelestimated TOA radiation change from the modeled TOA radiation change, normalizing by the surface temperature change. 
Following Goosse et al. (2018), we also calculate feedback contributions to polar warming $(\Delta T S)$ by dividing the energetic contribution of each feedback $\left(\lambda_{i} \Delta T S\right), \mathrm{CO}_{2}$ forcing $(\mathrm{F})$, change in atmospheric heat transport convergence $(\triangle \mathrm{AHT})$, and residual term (R $\Delta T S)$ by the magnitude of the Planck response in either the control Antarctic (Figure 3b) or control Arctic (Figure 3c) $\left(\lambda_{p, c}\right)$, where $\lambda_{p}^{\prime}=\lambda_{p}-\lambda_{p, c}$ is the difference between the local Planck response $\left(\lambda_{p}\right)$ and $\lambda_{p, c}$ :

$$
\Delta T S=-F / \lambda_{p, c}-\lambda_{p}^{\prime} \Delta T S / \lambda_{p, c}-\sum_{i} \lambda_{i} \Delta T S / \lambda_{p, c}-\Delta A H T / \lambda_{p, c}-R \Delta T S / \lambda_{p, c} .
$$

For this study, changes in climate variables are obtained from the doubled $\mathrm{CO}_{2}$ minus preindustrial simulations, and radiative kernels are taken from Shell et al. (2008), calculated with an offline radiative transfer version of the Community Atmospheric Model, version 3 (CAM3). Feedbacks are calculated with respect to local rather than global surface temperature change (Armour et al., 2013; Feldl \& Roe, 2013), and Arctic and Antarctic regional averages are defined for 70 to $90^{\circ} \mathrm{N}$ and ${ }^{\circ} \mathrm{S}$, respectively.

For the flat Antarctica experiment, we apply zonally averaged kernels from the Arctic between 60 and $90^{\circ} \mathrm{N}$ to the flat Antarctic between 60 and $90^{\circ} \mathrm{S}$, shifted by six months. As the standard kernels do not exist below the Antarctic surface elevation, this allows for feedback calculation with the assumption that climate variable effects on TOA radiation for the flat Antarctic are similar to the Arctic. We note that radiative kernels are affected by climatological characteristics such as cloud patterns and land-ocean distributions, which differ between hemispheres. However, the flipped kernel method is supported by similar climatological winter temperature profiles in the flat Antarctic and control Arctic, with similar inversion depth and intensity (Section 3.I) and representative profiles (Figure S la). We note that summer temperatures are colder in the flat Antarctic than the Arctic (Figure SIb) likely due to the 
absence of leads over Antarctica. Nevertheless, both summer and winter demonstrate strong agreement between the modeled and kernel-estimated longwave (LW) TOA radiation change in the flat Antarctic (Figure S2). Annual LW and shortwave (SW) kernel-estimated changes in TOA radiation approximate the modeled TOA radiation change for the flat Antarctic almost as well as the control Antarctic experiments (Figure S3), further supporting this flipped kernel method. An alternative estimation of the SW feedbacks using the approximate partial radiative perturbation (APRP) technique (Taylor et al., 2007) produces control and flat Antarctic feedbacks that are qualitatively similar to those calculated using the kernel method (Figure S9).

\subsection{Atmospheric Heat Transport}

We calculate AHT across each latitude using the poleward integral of the difference between TOA and surface energy fluxes (and seasonal atmospheric energy storage for seasonal averages) from monthly model output (e.g., Kay et al., 20I2; Donohoe et al., 2020a). We calculate latent heat transport as the poleward integral of evaporation minus precipitation at a given latitude, multiplied by the latent heat of vaporization, and dry static AHT as the residual between total AHT and latent AHT. As in Kay et al. (20I2), we estimate polar AHT convergence by dividing the change in $\mathrm{AHT}$ at the edge of polar regions by the surface area of these regions. The change in AHT is then normalized by the Planck feedback for the AHT warming contribution and by the polar surface temperature change for the AHT feedback. We also determine the vertical structure of AHT due to stationary eddies (SE) and transient eddies (TE) from CESM monthly output at $60^{\circ} \mathrm{N}$ and $60^{\circ} \mathrm{S}$. For the vertical structure of TE transport, we neglect the potential energy term in Donohoe et al. (2020), which is small at high latitudes. Vertical structures of SE and TE are calculated as:

$$
\mathrm{SE}=\left[\bar{V}^{*} \overline{M S E}^{*}\right]
$$


162 and

$$
\mathrm{TE}=\left[c_{p}(\overline{V T}-\bar{V} \bar{T})+L(\overline{V Q}-\bar{V} \bar{Q})\right]
$$

where $V$ is meridional velocity, MSE is moist static energy, $c_{p}$ is the specific heat of air, $L$ is the latent heat of vaporization of water, $T$ is atmospheric temperature, and $Q$ is specific humidity. Square brackets indicate zonal averages, overbars indicate monthly means, and asterisks denote departures from the zonal mean.

For comparison with CESM, we include vertical profiles of AHT and temperature from the ERA-Interim (Dee et al., 20I I) and NCEP-NCAR (Kalnay et al. 1996) reanalyses, using 6hourly fields for 1979-2018 to calculate SE and TE following Donohoe et al. (2020).

2.4 Inversion Depth and Intensity

Following Zhang et al. (20II), we define surface-based inversion depth as the geopotential thickness between the surface pressure and the first pressure level above which temperature decreases with height, and inversion intensity as the difference in temperature between these two levels.

\section{Results}

3. I Climatological polar inversion asymmetry

Antarctic surface elevation drives modeled differences in base-state surface inversion depth and intensity between the poles. Using the CESM preindustrial control simulation during Arctic winter, Figure la shows a schematic of radiative-advective equilibrium, which controls base-state inversions in polar regions (Cronin and Jansen, 20I5; Payne et al., 20I5). In this framework, LW cooling and weak surface solar absorption promote cold near-surface temperatures, while poleward $\mathrm{AHT}$ (shown at $60^{\circ} \mathrm{N}$ ) maintains warmer temperatures aloft. As is also seen in the NCEP and ERA-Interim reanalyses (Figure S4), AHT supporting these 
inversions maximizes in the lower troposphere (around $900 \mathrm{hPa}$ ), near the tropospheric temperature maximum. We propose that surface elevations above this level of maximum AHT promote shallower, radiatively-driven winter inversions in the Antarctic (Figure Ib). This preindustrial temperature profile at $90^{\circ} \mathrm{S}$ demonstrates CESM's ability to resolve shallow surface inversions (here $50 \mathrm{hPa}$ deep) matching radiosonde observations over the Antarctic Plateau, although the model underestimates the intensity of observed mean wintertime inversions which exceed $20 \mathrm{~K}$ at South Pole Station (Hudson \& Brandt, 2005). Weaker winter inversions over coastal slopes in CESM (Figure 2a; Figure S5d) align well with coastal Antarctic radiosonde observations, which indicate typical depths shallower than $300 \mathrm{~m}$ and intensities less than $5 \mathrm{~K}$ (Zhang et al., 20I I).

Considering CESM preindustrial winter inversion depth over the entire control Antarctic ice sheet, the deepest inversions are found where surface elevations are below the level of maximum poleward AHT (black contour, Figure 2a). Shallower winter inversions exist over the Antarctic Plateau, and inversion depth generally increases with increasing surface pressure over Antarctica (Figure 2b). Points with shallow inversions for a given surface pressure are located on (grey points, Figure $2 b$ ) or at the bottom of (boxed points, Figure 2b; stippling, Figure 2a) steep slopes (Figure S5a), where inversions may be disturbed by mixing due to katabatic winds (Vihma et al., 20II).

In contrast to Antarctica, most points in the Arctic are at higher surface pressures, allowing AHT to support deep inversions (Figure 2c, S5c). Inversions are shallower over the Greenland ice sheet, particularly over steep slopes, and in regions with low sea-ice fraction. While intense, shallow inversions (Figure S5d) exist at high Antarctic elevations, many areas show weaker inversion intensity than the Arctic (Figure S5f), especially over steep Antarctic 
slopes. These inversions in CESM are consistent with radiosonde observations of generally shallower, weaker inversions in the Antarctic compared to the Arctic (Zhang et al., 20I I).

In comparison to the control Antarctic, inversions in the flat Antarctic preindustrial experiment are intensified and deepened, particularly over steep slopes (Figures S5b,e, S6a,b). An average inversion depth of $583 \mathrm{~m}$ and intensity of $7.5 \mathrm{~K}$ over the control Antarctic increases to $846 \mathrm{~m}$ and II.9 $\mathrm{K}$ over the flat Antarctic, more comparable with the average inversion depth of $854 \mathrm{~m}$ and intensity of $9.0 \mathrm{~K}$ in the Arctic. We next investigate the extent to which these stronger, deeper climatological inversions in the flat Antarctic simulation, which more closely resemble Arctic inversions, may promote an Arctic-like lapse-rate feedback and stronger Antarctic amplification.

\subsection{Polar amplification and lapse-rate feedback asymmetry}

In contrast to control Antarctic warming $(5.4 \mathrm{~K})$ under doubled $\mathrm{CO}_{2}$, flat Antarctic warming $(6.3 \mathrm{~K})$ is more comparable to control Arctic warming $(6.7 \mathrm{~K}$; Figure 3a) in the annual mean. Applying Eq. (I), we find that the largest contributor to stronger amplification in the flat Antarctic is the lapse-rate feedback (Figure 3b). A more-positive water-vapor feedback and $\triangle \mathrm{AHT}$ also support enhanced flat Antarctic warming, while more-negative Planck and cloud feedbacks and a less-positive albedo feedback oppose flat Antarctic warming. The LW residual term is similar for the control and flat Antarctic, although the SW residual term is slightly larger in the flat Antarctic (Figure S7a). Flat Antarctica experiences lapse-rate, water-vapor, and Planck warming contributions nearly equivalent to the Arctic, while a larger $\triangle \mathrm{AHT}$ and residual term in the flat Antarctic partly balance more-positive albedo and cloud feedbacks in the Arctic (Figure 3c). 
Figures S7b-g show the response to $\mathrm{CO}_{2}$ doubling for flat minus control Antarctic topography experiments for various climate variables relevant for feedbacks (left) and the difference for the radiative kernels (right), where $T$ is atmospheric temperature, TS is surface temperature, $q$ is specific humidity, and $\alpha$ is albedo. The strengthened lapse-rate feedback in the flat Antarctic is supported both by more surface-trapped warming in response to $\mathrm{CO}_{2}$ doubling (more-negative $\Delta(T-T S)$ ), and by a more-negative $T$ kernel due to deepening and moistening the atmospheric column (Figure S7b,c). While it is difficult to quantify exactly how much of the increased lapse-rate feedback in the flat versus control Antarctic stems from the deeper troposphere alone, we find that only $26 \%$ of this increase can be obtained from simply extending the control Antarctic $\Delta(T-T S)$ from the lowest elevations above the ice sheet to all pressure levels below the ice sheet and multiplying by the flat Antarctic temperature kernel. This suggests that the increased lapse-rate feedback over flat Antarctica is strongly driven by enhanced surface-trapped warming, rather than simply a deeper atmospheric column.

Surface-trapped warming enhancement for the flat Antarctic appears largest over the Transantarctic Mountains and coastal slopes, where steep slopes promote shallow, weak inversions in the control topography experiment (Figure S7b). Particularly for these regions, increased preindustrial inversion depth and intensity in the flat experiment support stronger low-level warming (Figure S6) and an enhanced lapse-rate feedback.

Both the stronger water-vapor feedback and weaker surface-albedo feedback in the flat Antarctic are supported by deepening and moistening the atmospheric column. This amplifies the greenhouse effect of water vapor by increasing the column-integrated specific humidity and strengthening the water-vapor kernel (Figure S7d,e). The deeper atmospheric column over flat Antarctica also dampens surface albedo impacts on TOA radiation, and this weaker (less- 
negative) albedo kernel (Figure S7g) drives a weakened albedo feedback in the flat Antarctic. Since feedbacks are normalized by local surface temperature change, the more-negative flat Antarctic Planck feedback shown in Figure S7a can be attributed to a stronger atmospheric temperature kernel due to a warmer, deeper emitting column.

The more-negative cloud feedback in the flat versus control Antarctic is explained by more-negative SW cloud forcing (Figure S8a; Figure SI Iaa). The flat Antarctic experiences a larger increase in cloud cover and cloud water path due to increased low-level liquid-bearing clouds under $\mathrm{CO}_{2}$ doubling (Figure S8d,e), supporting a stronger negative SW cloud feedback. Preindustrial cloud water path (not shown) is also larger for the flat Antarctic, likely due to an extended lower atmosphere, enhanced water-vapor transport, and increased stability. Areas of stronger sea-ice loss (Figure S8c) for the flat Antarctic also correspond to increased cloud water path and SW forcing.

Increased preindustrial AHT toward the Antarctic balances stronger cooling to space over flat Antarctica (Figure SIOa), consistent with Singh et al. (20I6) and Salzmann (20I7). Under doubled $\mathrm{CO}_{2}$, AHT to the flat Antarctic also increases more, largely due to enhanced southward latent AHT (Figure SIOb). $\triangle \mathrm{AHT}$ and feedback calculations for these slab ocean experiments using the kernel method produce similar results to Salzmann (20I7), who employ partial radiative perturbation (PRP) feedback computations for the transient response to $\mathrm{CO}_{2}$ doubling in fully-coupled runs: flat Antarctica experiences stronger lapse-rate and water-vapor feedbacks and increased poleward $\triangle \mathrm{AHT}$, opposed by more-negative Planck and cloud feedbacks and a less-positive albedo feedback.

3.3 Radiative feedback contributions to seasonality in Arctic and Antarctic amplification 

experiment occurs predominantly during the winter season (Figure 4a-c), with similar summer warming for flat and control experiments. This produces a greater difference between winter 278 and summer warming $(4.0 \mathrm{~K})$ in the flat Antarctic compared to the elevated Antarctic (2.I K), 279 more comparable with control Arctic warming seasonality (5.3 K). To investigate what causes 280 enhanced seasonality in warming in the flat Antarctic experiment, we compare winter and 28I summer climate feedbacks. Feedbacks shown are normalized by the annual-mean local warming, 282 although we find similar results for normalizing by seasonal warming. Figures $4 d-i$ highlight seasonal lapse-rate and SW cloud feedbacks, with seasonality for all feedbacks shown in Figure 284 SII.

In the Arctic, the lapse-rate feedback strongly promotes greater warming in winter than summer (Figure 4f), consistent with Pithan and Mauritsen (20I4). This enhanced winter lapserate feedback is driven by stronger base-state inversions in winter compared to summer, when sea-ice melting keeps surface temperatures near the freezing point. While strong lapse-rate

289 feedback seasonality occurs over Southern Ocean sea ice, seasonality in this feedback is weaker over Antarctica for both the control and flat experiments. Flat Antarctica experiences stronger 29I seasonality in warming than control Antarctica due in part to strengthened winter inversions, 292 but the primary feedback enhancing flat Antarctic warming seasonality is the SW cloud 293 feedback.

295 occurs exclusively during summer (Figure 4h). While the lapse-rate and water-vapor feedbacks 296 promote greater warming for the flat Antarctic throughout the year, greater warming 297 seasonality over flat Antarctica results largely from the SW cloud feedback damping only 
summertime warming. About two thirds of the difference in SW cloud feedback seasonality between control and flat Antarctica arises from cloud radiative forcing, with the other third coming from differences in the cloud masking term. A weaker summer surface albedo feedback over flat Antarctica also contributes slightly to stronger winter versus summer warming, with stronger albedo feedback seasonality changes over sea ice (Figure SI Id).

\section{Conclusions}

With a goal of understanding the mechanisms driving lapse-rate feedback differences between the Arctic and Antarctic, we compare CESM slab ocean experiments with control and flattened Antarctic topography under preindustrial and doubled $\mathrm{CO}_{2}$ forcing. We find climatological differences in CESM preindustrial Arctic and Antarctic inversions, supported by radiosonde observations. Limited poleward atmospheric heat transport above ice sheet elevations, in addition to mixing due to katabatic winds on steep slopes, drives shallower, weaker inversions for the Antarctic than the Arctic. Combined with weaker emission from the relatively shallow and dry Antarctic atmospheric column, these weaker Antarctic inversions prohibit the strong positive lapse-rate feedback seen in the Arctic. In contrast, over the flat Antarctic, stronger climatological inversions support a lapse-rate feedback that is comparable to that in the Arctic, with nearly equivalent degrees of polar amplification in each hemisphere in these slab ocean experiments. While the seasonality of warming in the flat Antarctic is also more comparable to the Arctic, this seasonality is supported by different climate feedbacks at each pole: lapse-rate feedback seasonality contributes strongly to enhanced winter warming in the Arctic, while a negative SW cloud feedback that only applies to non-winter months contributes more to flat Antarctic seasonality. 
As noted by Salzmann (2017), enhanced Antarctic amplification in flat Antarctica

experiments suggests that reduced Antarctic surface elevation due to mass loss would accelerate Antarctic amplification under climate change. In the context of previous studies considering the relative roles of sea ice and the lapse-rate feedback for polar amplification (e.g., Graversen et al., 2014; Dai et al., 2019), investigating Antarctic amplification can also provide insight into mechanisms supporting Arctic amplification. Flat Antarctic experiments here and in Salzmann (2017) demonstrate that strong, Arctic-like polar amplification is possible without local sea-ice loss, although non-local sea-ice loss in the Southern Ocean likely contributes to Antarctic amplification through changes in AHT. Our experiments additionally indicate that the strongest seasonality in the lapse-rate feedback occurs in regions with sea ice: even over the flattened Antarctic continent, lapse-rate feedback seasonality pales in comparison to lapse-rate feedback seasonality over the Southern Ocean and Arctic. In line with Cronin and Jansen (20I5) and Payne et al. (20I5), enhanced flat Antarctic warming supports the dependence of the lapserate feedback on base-state inversions, which themselves depend on sea-ice concentration and surface albedo in the Arctic. Further work to disentangle the lapse-rate feedback from sea-ice effects may clarify how they will change separately and in tandem under climate change.

\section{Acknowledgments}

LCH was supported by the National Science Foundation (NSF) Graduate Research Fellowship Grant DGE-1762 I I4. KCA was supported by NSF Awards AGS-I 752796 and OCE-I850900. AD was supported by the NSF Antarctic Program Grant PLR I643436. CMB and ASP were supported by the National Science Foundation Antarctic Program Grant OPP-1602435. We acknowledge high-performance computing support from Cheyenne and data storage provided by NCAR's Computational and Information Systems Laboratory (2019), sponsored by the NSF. CESM model output relevant for study figures is available at https://doi.org/I0.528I/zenodo.373544I (Hahn et al., 2020). ERA-Interim data was provided by the ECMWF Data Archive at https://apps.ecmwf.int/datasets/data/interim-full-daily/levtype=pl/, and NCEP data was provided at https://www.esrl.noaa.gov/psd/ by the NOAA/OAR/ESRL PSD, Boulder, Colorado. 


\section{References}

Armour, K. C., Bitz, C. M., \& Roe, G. H. (20I3). Time-varying climate sensitivity from regional feedbacks. Journal of Climate, 26, 45 I8-4534. https://doi.org/ I0.I I 75/JCLI-D- I2-00544. I

Armour, K. C., Marshall, J., Scott, J., Donohoe A., \& Newsom, E. R. (2016). Southern Ocean warming delayed by circumpolar upwelling and equatorward transport. Nature Geoscience, 9, 549-554. https://doi.org//0.1038/ngeo2731

Bintanja, R., \& van der Linden, E. (2013). The changing seasonal climate in the Arctic. Scientific Reports, 3, 1556. https://doi.org/10.1038/srep01556

Bitz, C.M., Shell, K.M., Gent, P.R., Bailey, D.A., Danabasoglu, G., Armour, K.C., Holland, M.M., \& Kiehl, J.T. (20I2). Climate Sensitivity of the Community Climate System Model, Version 4. Journal of Climate, 25, 3053-3070. https://doi.org/ I0.I I 75//CLI-D-I I-00290. I

Collins, M., Knutti, R., Arblaster, J., Dufresne, J-L., Fichefet, T., Friedlingstein, P., et al. (20I3). Long-term climate change: Projections, commitments and irreversibility. In T. F. Stocker, D. Qin, G-K. Plattner, M. M. B. Tignor, S. K. Allen, J. Boschung, et al. (Eds.), Climate Change 2013 - The Physical Science Basis: Contribution of Working Group I to the Fifth Assessment Report of the Intergovernmental Panel on Climate Change (pp. I029-I I 36). (Intergovernmental Panel on Climate Change). New York, NY: Cambridge University Press.

Computational and Information Systems Laboratory (20I9). Cheyenne: HPE/SGI ICE XA System (Climate Simulation Laboratory). Boulder, CO: National Center for Atmospheric Research. https://doi.org// 0.5065/D6RX99HX

Cronin, T. W., \& Jansen, M. F. (2016). Analytic radiative-advective equilibrium as a model for high-latitude climate. Geophysical Research Letters, 43, 449-457.

https://doi.org/10.1002/2015GL067/72

Danabasoglu, G., \& Gent, P.R. (2009). Equilibrium climate sensitivity: Is it accurate to use a slab ocean model? Journal of Climate, 22, 2494-2499. https://doi.org/I0.I I75/2008JCLI2596.I

Dai, A., Luo, D., Song, M., \& Liu, J. (2019). Arctic amplification is caused by sea-ice loss under increasing $\mathrm{CO}_{2}$. Nature Communications, 10, I 2 I. https://doi.org/I0.1038/s4I467-0 I8-07954-9

Dee, D. P., Uppala, S. M., Simmons, A. J., Berrisford, P., Poli, P., Kobayashi, S., et al. (20I I). The ERAInterim reanalysis: Configuration and performance of the data assimilation system. Quarterly Journal of the Royal Meteorological Society, 137, 553-597. https://doi.org/I0.1002/qj.828

Donohoe, A., Armour, K. C., Roe, G. H., Battisti, D. S., \& Hahn, L. (2020). The partitioning of meridional heat transport from the Last Glacial Maximum to $\mathrm{CO}_{2}$ quadrupling in coupled climate models. Journal of Climate, 33, 4I4 I-4 I65. https://doi.org/ 10.1 I75//CLI-D-19-0797.I 
Feldl, N., \& Roe, G. H. (2013). Four perspectives on climate feedbacks. Geophysical Research Letters, 40, 4007-40II. https://doi.org/I0.1002/grl.507II

Feldl, N., Bordoni, S., \& Merlis, T. M. (2017). Coupled high-latitude climate feedbacks and their impact on atmospheric heat transport. Journal of Climate, 30, I89-201.

https://doi.org/I0.1 I75/JCLI-D-16-0324.I

Goosse, H., Kay, J. E., Armour, K. C., Bodas-Salcedo, A., Chepfer, H., Docquier, D., et al. (20I8). Quantifying climate feedbacks in polar regions. Nature Communications, 9, 1919. https://doi.org/10.1038/s41467-018-04173-0

Graversen, R. G., Langen, P. L., \& Mauritsen, T. (20I4). Polar amplification in CCSM4: Contributions from the lapse rate and surface albedo feedbacks. Journal of Climate, 27, 44334450. https://doi.org/10.1 175//CLI-D-13-0055I.I

Hahn, L. C., Armour, K. C., Battisti, D. S., Donohoe, A., Pauling, A. G., \& Bitz, C. M. (2020). Supporting Data for Hahn et al. GRL: Antarctic elevation drives hemispheric asymmetry in polar lapse-rate climatology and feedback [Data set]. Zenodo. http://doi.org/ / 0.528I/zenodo.3735442

Hudson, S. R., \& Brandt, R. E. (2005). A look at the surface-based temperature inversion on the Antarctic Plateau. Journal of Climate, 18, 1673-1696. https://doi.org//0.1 I75/JCLI3360.I

Hunke, E., \& Lipscomb, W. (2008). CICE: The Los Alamos sea ice model, documentation and software, version 4.0 (Tech. Rep. LA-CC-06-0I2). Los Alamos, NM: Los Alamos National Laboratory.

Hurrell, J. W., Holland, M. M., Gent, P. R., Ghan, S., Kay, J. E., Kushner, P. J., et al. (20I3). The Community Earth System Model: A framework for collaborative research. Bulletin of the American Meteorological Society, 94(9), 1339-1360. https://doi.org/I0.1 I75/BAMS-D-12-00I2I.I

Kalnay, E., Kanamitsu, M., Kirtler, R., Collins, W., Deaven, D., Gandin, L., et al. (1996). The NCEP/NCAR 40-year reanalysis project. Bulletin of the American Meteorological Society, 77(3), 437-47I. https://doi.org/I0.I I 75/I520-0477(I 996)077<0437:TNYRP>2.0.CO;2

Kay, J. E., Holland, M. M., Bitz, C. M., Blanchard-Wrigglesworth, E., Gettelman, A., Conley, A., \& Bailey, D. (20I2). The influence of local feedbacks and northward heat transport on the equilibrium Arctic climate response to increased greenhouse gas forcing. Journal of Climate, 25(I6), 5433-5450. https://doi.org/I0.I I75/jcli-d-I I-00622.I

Marshall, J., Scott, J.R., Armour, K.C., Campin, J.-M., Kelley, M., \& Romanou, A. (20I5). The ocean's role in the transient response of climate to abrupt greenhouse gas forcing. Climate Dynamics, 44, 2287-2299. https://doi.org/10.1007/s00382-014-2308-0

Neale, R. B., Richter, J., Park, S., Lauritzen, P. H., Vavrus, S. J., Rasch, P. J., \& Zhang, M. (20I3). The mean climate of the Community Atmosphere Model (CAM4) in forced SST and 
fully coupled experiments. Journal of Climate, 26, 5I50-5 168. https://doi.org//0.1 I75//CLI-D-I200236.1

Oleson, K., Lawrence, D., Bonan, G., Flanner, M., Kluzek, E., Lawrence, P., et al. (20I0). Technical description of version 4.0 of the Community Land Model (CLM) (Tech. Rep. TN478+STR). Boulder, CO: National Center for Atmospheric Research.

Payne, A. E., Jansen, M. F., \& Cronin, T. W. (2015). Conceptual model analysis of the influence of temperature feedbacks on polar amplification. Geophysical Research Letters, 42, 956I-9570. https://doi.org// 0.1002/2015GL065889

Pithan, F., \& Mauritsen, T. (2014). Arctic amplification dominated by temperature feedbacks in contemporary climate models. Nature Geoscience, 7, I8I-184. https://doi.org//0.1038/ngeo2071

Po-Chedley, S., Armour, K. C., Bitz, C. M., Zelinka, M. D., Santer, B. D., \& Fu, Q. (20I8). Sources of intermodel spread in the lapse rate and water vapor feedbacks. Journal of Climate, 3/ (8), 3187-3206. https://doi.org//0.1 I75//CLL-D-17-0674.I

Richter, J. H., Solomon, A., \& and Bacmeister, J. T. (20/4). Effects of vertical resolution and nonorographic gravity wave drag on the simulated climate in the Community Atmosphere Model, version 5. Journal of Advances in Modeling Earth Systems, 6, 357-383. https://doi.org/I0.1002/20I3MS000303

Salzmann, M. (2017). The polar amplification asymmetry: role of Antarctic surface height. Earth System Dynamics, 8, 323-336. https://doi.org/I0.5194/esd-8-323-2017

Screen, J. A., \& Simmonds, I. (2010a). The central role of diminishing sea ice in recent Arctic temperature amplification. Nature, 464, I334-1337. https://doi.org// 0.1038/nature0905 I

Screen, J. A., \& Simmonds, I. (20I0b). Increasing fall-winter energy loss from the Arctic Ocean and its role in Arctic temperature amplification. Geophysical Research Letters, 37, LI6707. https://doi.org// 0.1029/2010GL044I36

Serreze, M. C., Barrett, A. P., Stroeve, J. C., Kindig, D. N., \& Holland, M. M. (2009). The emergence of surface-based Arctic amplification. The Cryosphere, 3, II-19. https://doi.org/ I0.5194/tc-3-II-2009

Shell, K. M., Kiehl, J. T., \& Shields, C. A. (2008). Using the radiative kernel technique to calculate climate feedbacks in NCAR's Community Atmospheric Model. Journal of Climate, 21, 22692282. https://doi.org//0.1175/2007/CLI2044.I

Singh, H. A., Bitz, C. M., \& Frierson, D. M. W. (2016). The global climate response to lowering surface orography of Antarctica and the importance of atmosphere-ocean coupling. Journal of Climate, 29(II), 4137-4I53. https://doi.org/I0.1 I75/JCLI-D-I5-0442.I 
Singh, H., Garuba, O., \& Rasch, P. (2018). How asymmetries between Arctic and Antarctic climate sensitivity are modified by the ocean. Geophysical Research Letters, 45, I3,03 I-I3,040. https://doi.org/I0.1029/2018GL079023

Smith, D. M., Screen, J. A., Deser, C., Cohen, J., Fyfe, J. C., García-Serrano, J., et al. (2019). The Polar Amplification Model Intercomparison Project (PAMIP) contribution to CMIP6: investigating the causes and consequences of polar amplification. Geoscientific Model Development, I2, II39-II64. https://doi.org/I0.5I94/gmd-I2-II39-2019

Soden, B. J., Held, I. M., Colman, R., Shell, K. M., Kiehl, J. T., \& Shield, C. A. (2008). Quantifying climate feedbacks using radiative kernels. Journal of Climate, 2 I, 3504-3520.

https://doi.org/|0.1 I75/2007/CLI2I I0.I

Taylor, K. E., Crucifix, M., Braconnot, P., Hewitt, C. D., Doutriaux, C., Broccoli, A. J., Mitchell, J. F. B., \& Webb, M. J. (2007). Estimating Shortwave Radiative Forcing and Response in Climate Models. Journal of Climate, 20, 2530-2543. https://doi.org//0.1 I75//CLI4|43.I

Vihma, T., Tuovinen, E., \& Savijärvi, H. (20I I). Interaction of katabatic winds and near-surface temperatures in the Antarctic. Journal of Geophysical Research, I I6, D2 III9. https://doi.org/10.1029/2010JD014917

Zhang, Y., Seidel, D. J., Golaz, J. C., Deser, C., \& Tomas, R. A. (20I I). Climatological characteristics of Arctic and Antarctic surface-based inversions. Journal of Climate, 24(19), 51675 I86. https://doi.org/ I0.1 I75/20 I IJCLI4004. I 

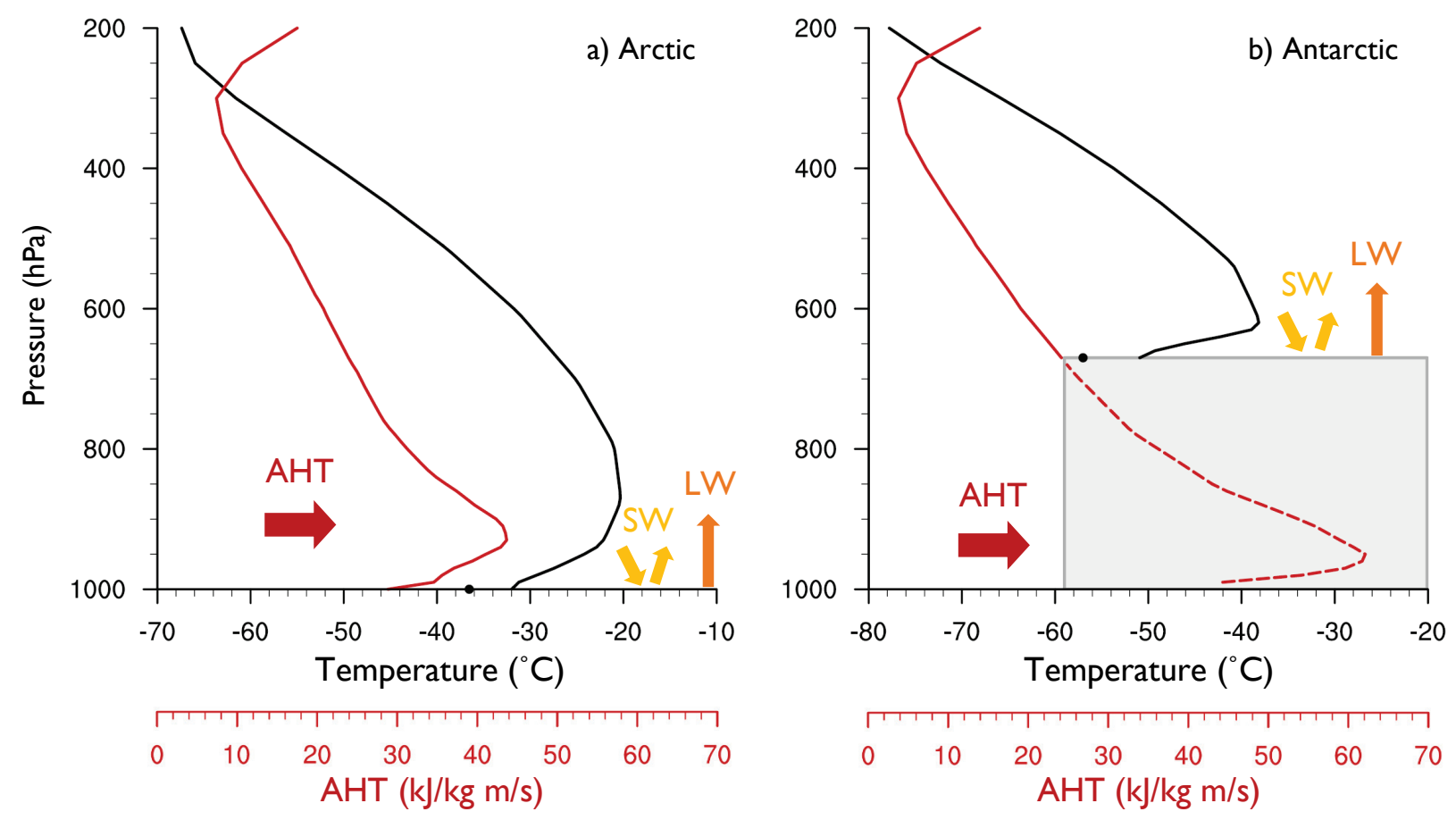

Figure I. Radiative-advective equilibrium schematic using the CESM preindustrial control topography temperature and AHT. Vertical profiles of winter poleward AHT due to transient and stationary eddies at (a) $60^{\circ} \mathrm{N}$ and (b) $60^{\circ} \mathrm{S}$ (red; kJ/kg m/s) and winter temperature at (a) $90^{\circ} \mathrm{N}$ and (b) $90^{\circ} \mathrm{S}$ (black; dot for surface temperature; ${ }^{\circ} \mathrm{C}$ ). 
a) Surface inversion depth $(\mathrm{m})$

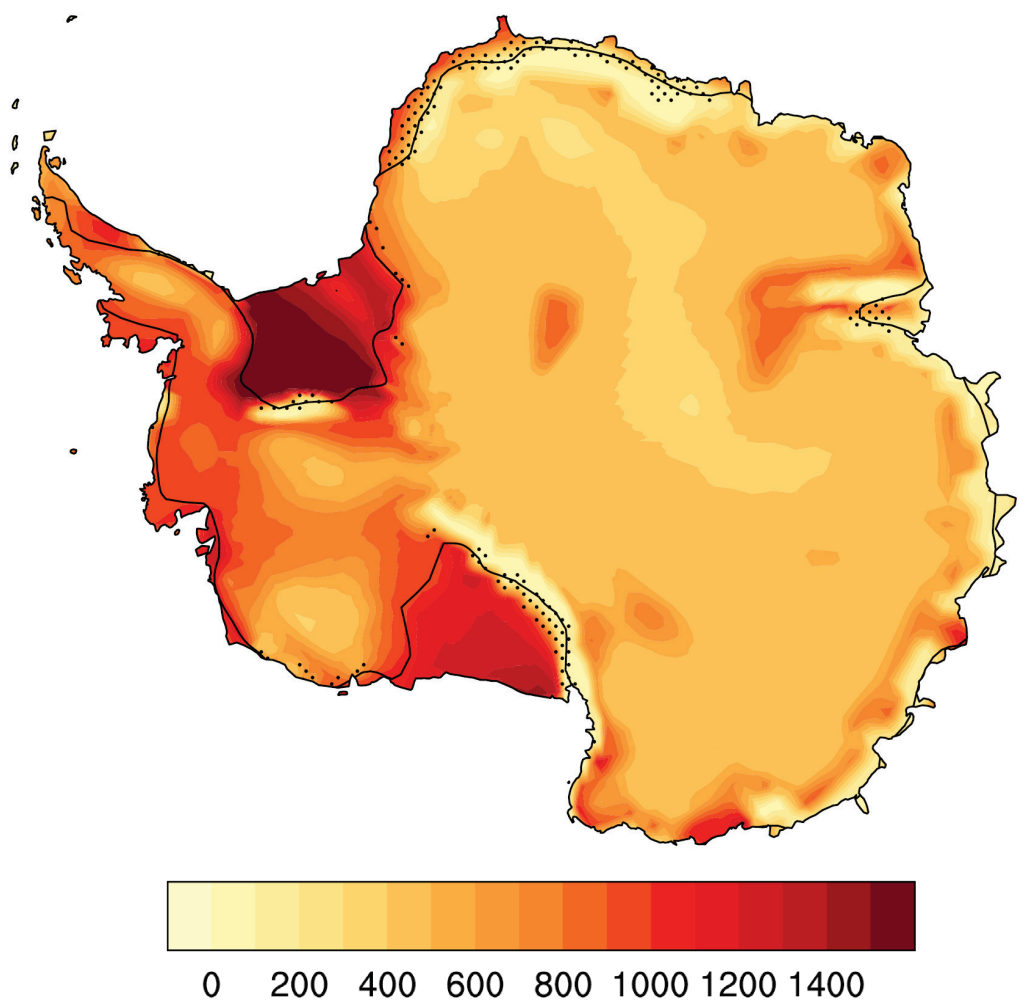

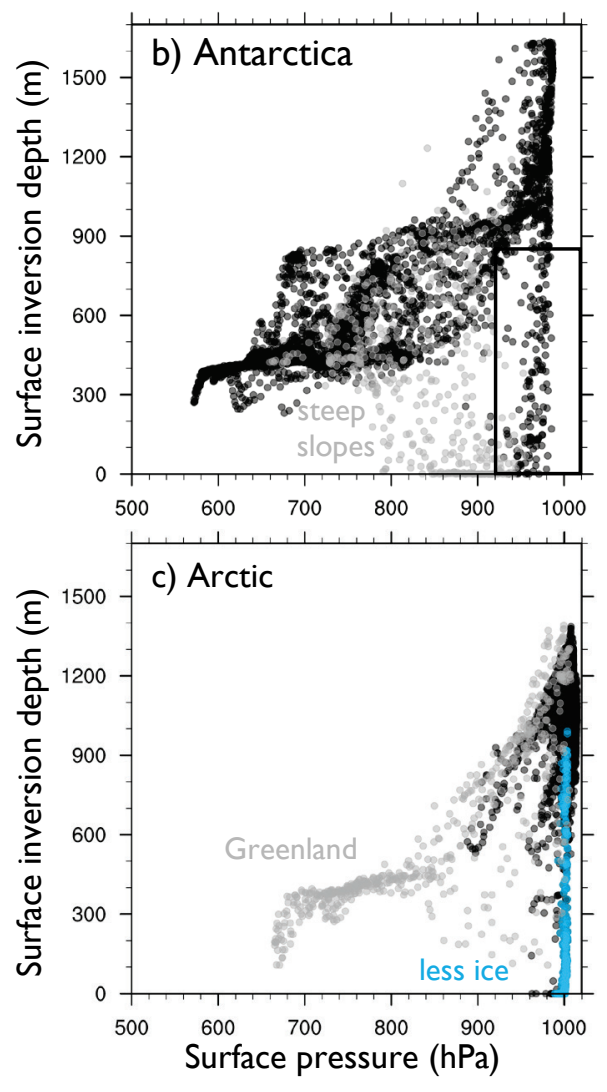

Figure 2. Winter surface-based inversion depth (m) for (a) Antarctica, (b) Antarctica from 70 to $90^{\circ} \mathrm{S}$, and (c) the Arctic from 70 to $90^{\circ} \mathrm{N}$ from the CESM preindustrial control topography experiment. Black contour in (a) shows where the winter surface pressure equals $950 \mathrm{hPa}$ : the level of the maximum AHT due to transient and stationary eddies during winter at $60^{\circ} \mathrm{S}$. Grey points in (b) indicate surface slopes greater than .007 . Boxed points in (b), with surface pressure greater than $920 \mathrm{hPa}$ and inversion depth less than $850 \mathrm{~m}$, correspond to stippled regions in (a). In (c), blue points indicate winter sea ice fraction less than .97, and grey points are located over Greenland. 
a) Annual near surface $\mathrm{T}$ change $\left({ }^{\circ} \mathrm{C}\right)$

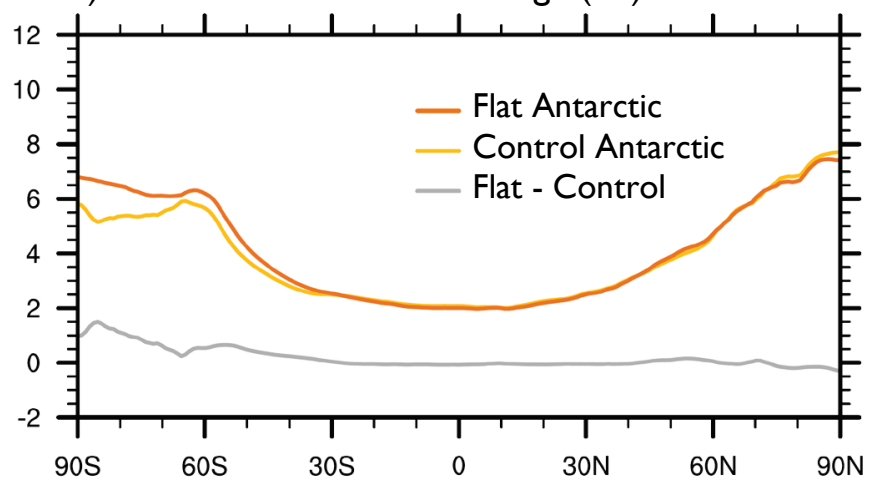

b) Antarctic warming contributions $\left({ }^{\circ} \mathrm{C}\right)$

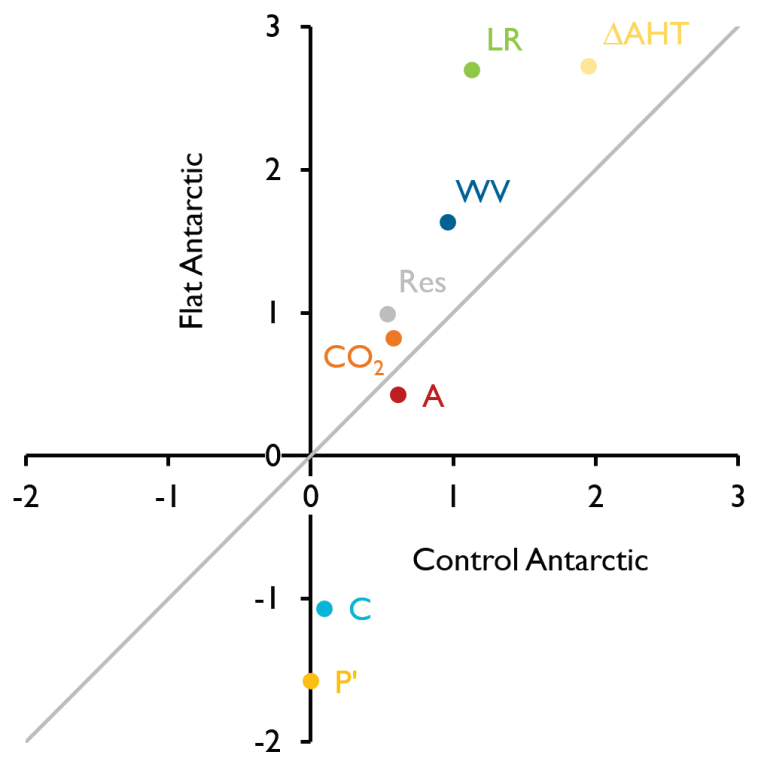

c) Polar warming contributions $\left({ }^{\circ} \mathrm{C}\right)$

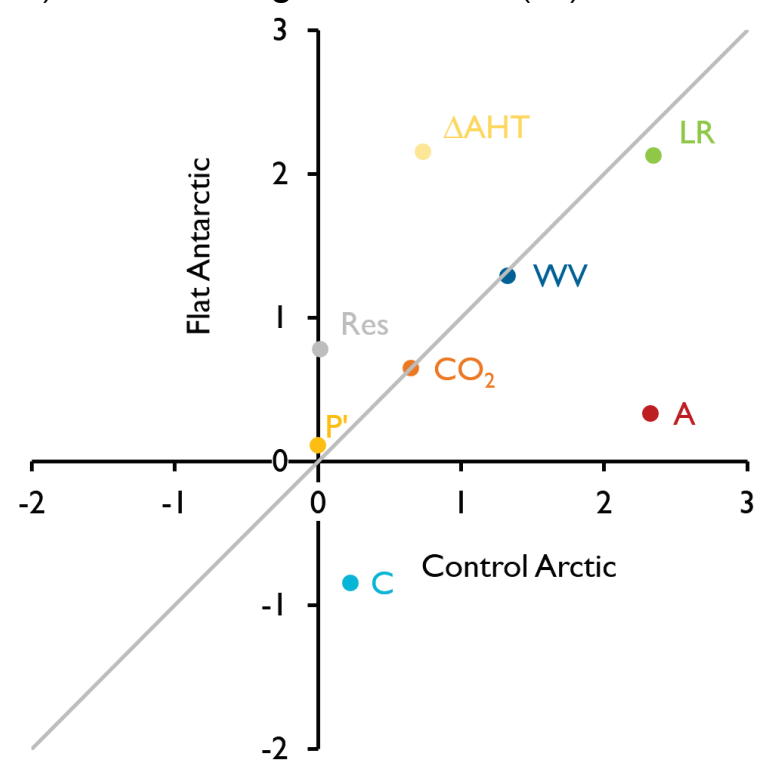

Figure 3. (a) Zonal- and annual-mean near-surface temperature change $\left({ }^{\circ} \mathrm{C}\right)$ under $\mathrm{CO}_{2}$ doubling in the control (yellow) and flat (orange) Antarctic experiments and their difference (grey); (b,c) Contributions of each feedback and atmospheric forcing to warming $\left({ }^{\circ} \mathrm{C}\right)$ for the flat Antarctic compared to (b) the control Antarctic and (c) the control Arctic for the lapse rate (LR), surface albedo (A), water vapor (WV), and cloud (C) feedbacks, the variation in the Planck response from its value in (b) the control Antarctic and (c) the control Arctic ( $\left.P^{\prime}\right)$, $\mathrm{CO}_{2}$ forcing $\left(\mathrm{CO}_{2}\right)$, change in $\mathrm{AHT}$ convergence $(\triangle \mathrm{AHT})$, and residual term (Res). 

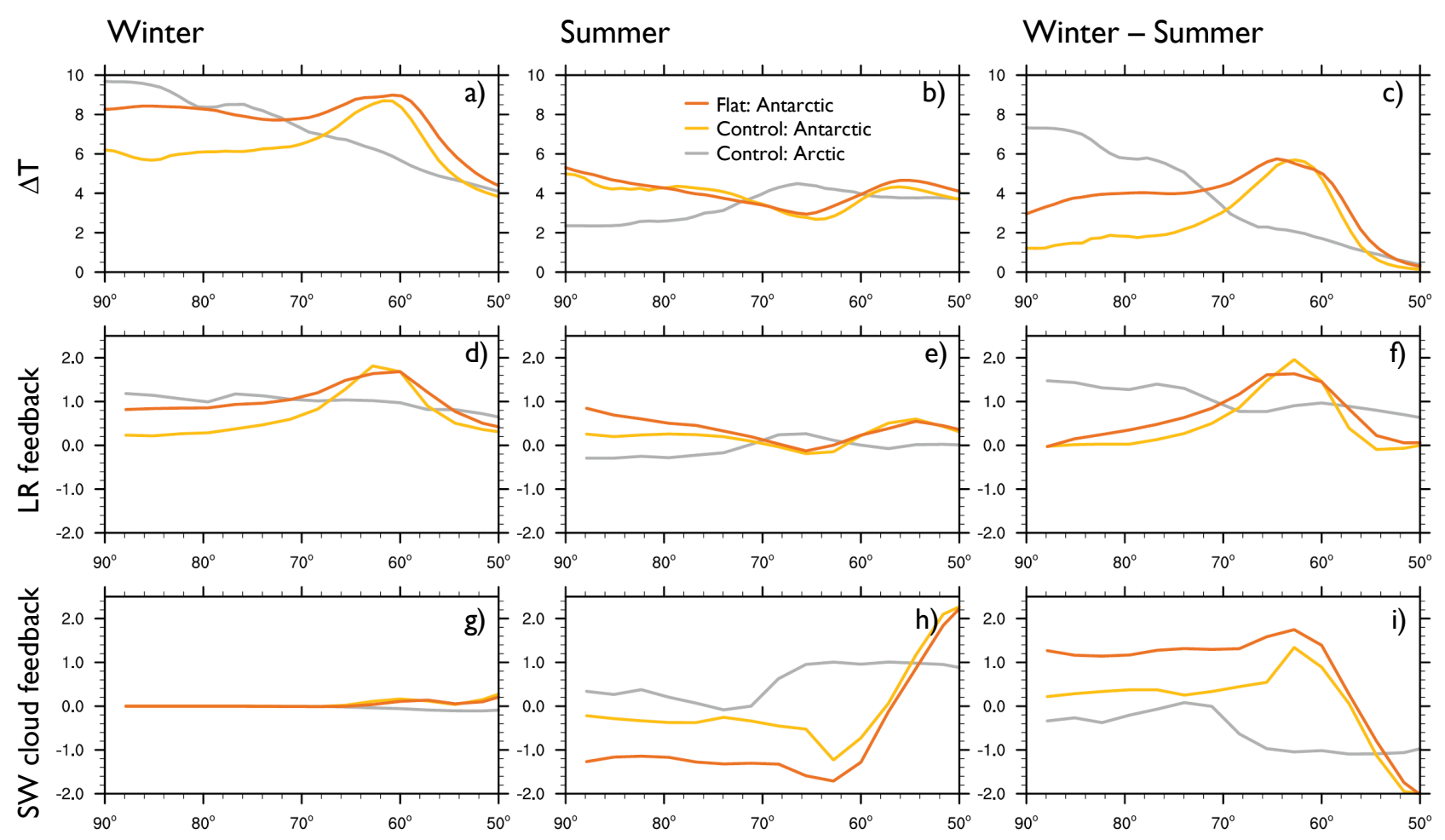

Figure 4. Zonal-mean (a-c) near surface temperature change $\left({ }^{\circ} \mathrm{C}\right)$, $(\mathrm{d}-\mathrm{f})$ lapse rate feedback $\left(\mathrm{W} / \mathrm{m}^{2} / \mathrm{K}\right)$, and $(\mathrm{g}-\mathrm{i})$ shortwave $(\mathrm{SW})$ cloud feedback $\left(\mathrm{W} / \mathrm{m}^{2} / \mathrm{K}\right)$ under $\mathrm{CO}_{2}$ doubling in the control Arctic (grey) and control (yellow) and flat (orange) Antarctic for (a,d,g) winter, (b,e,h) summer, and (c,f,i) winter minus summer. 